\title{
The Impact of Frequency in Surveying Engineering Slopes Using Ground Penetrating Radar
}

\author{
Angelo Indelicato \\ Dragages Hong Kong Ltd., Hong Kong, China \\ Email: angelo_indelicato@hotmail.com
}

How to cite this paper: Indelicato, A. (2017) The Impact of Frequency in Surveying Engineering Slopes Using Ground Penetrating Radar. International Journal of Geosciences, 8, 296-304. https://doi.org/10.4236/ijg.2017.83014

Received: November 16, 2016

Accepted: March 24, 2017

Published: March 28, 2017

Copyright $\odot 2017$ by author and Scientific Research Publishing Inc. This work is licensed under the Creative Commons Attribution International License (CC BY 4.0).

http://creativecommons.org/licenses/by/4.0/ (c) (i) Open Access

\begin{abstract}
Ground Penetrating Radar (GPR) is one of the non-invasive techniques commonly used to identify "anomalies" in the ground. It has been proven very effective in different fields ranging from the location of pipes and other underground services to the identification of archaeological sites. After the 1994 Kwun Lung Lau accident in Hong Kong, the Government has been commissioning the feasibility of different geophysics techniques to identify any issues related to engineering slopes and retaining walls. Among the different techniques tested during phase I, Electrical Imaging (EI) and Ground Penetrating Radar (GPR) were the most applicable in the study of old masonry walls. This paper aims to stress the importance of using the appropriate frequencies during the GPR survey of engineering slopes. In order to do that, two independent contractors who used different frequencies to carry out the GPR survey on the same area will be compared.
\end{abstract}

\section{Keywords}

Ground Penetrating Radar, Slope, Survey, Hong Kong

\section{Introduction}

Ground Penetrating Radar, or GPR, is a non-invasive technology used to study subsurface stratigraphy. It employs electromagnetic waves with frequencies between $10 \mathrm{MHz}$ and $4 \mathrm{GHz}$ to detect changes in electrical properties [1].

The electromagnetic waves are essentially the same as the radio waves that a car radio antenna receives from a broadcasting radio station. The reflection of the waves is due to the different dielectric properties of the material under the surface. The dielectric difference of an object within the ground produces a reflected wave. Using the reflections, a cross sectional reflection profile is created. 
Since its first use, GPR has gained popularity as a shallow subsurface geophysical imaging tool due to its ease of use, portable recording and high-resolution section [2]. It has been successfully applied to very diverse tasks ranging from the geological mapping of structures to the identification of defects in concrete [3].

The use of this technique in the survey of old retaining walls was first considered in 1994 after the collapse of the old retaining wall in Kwun Lung Lau on Hong Kong Island. During this event, $1000 \mathrm{~m}^{3}$ of debris ended up in the pathway, killing 5 people and injuring 3 others. For this reason, the Hong Kong Government was adamant in evaluating the potential of a geophysical survey to define the thickness of the retaining wall.

Retaining structures (Figure 1) in Hong Kong have been classified mainly
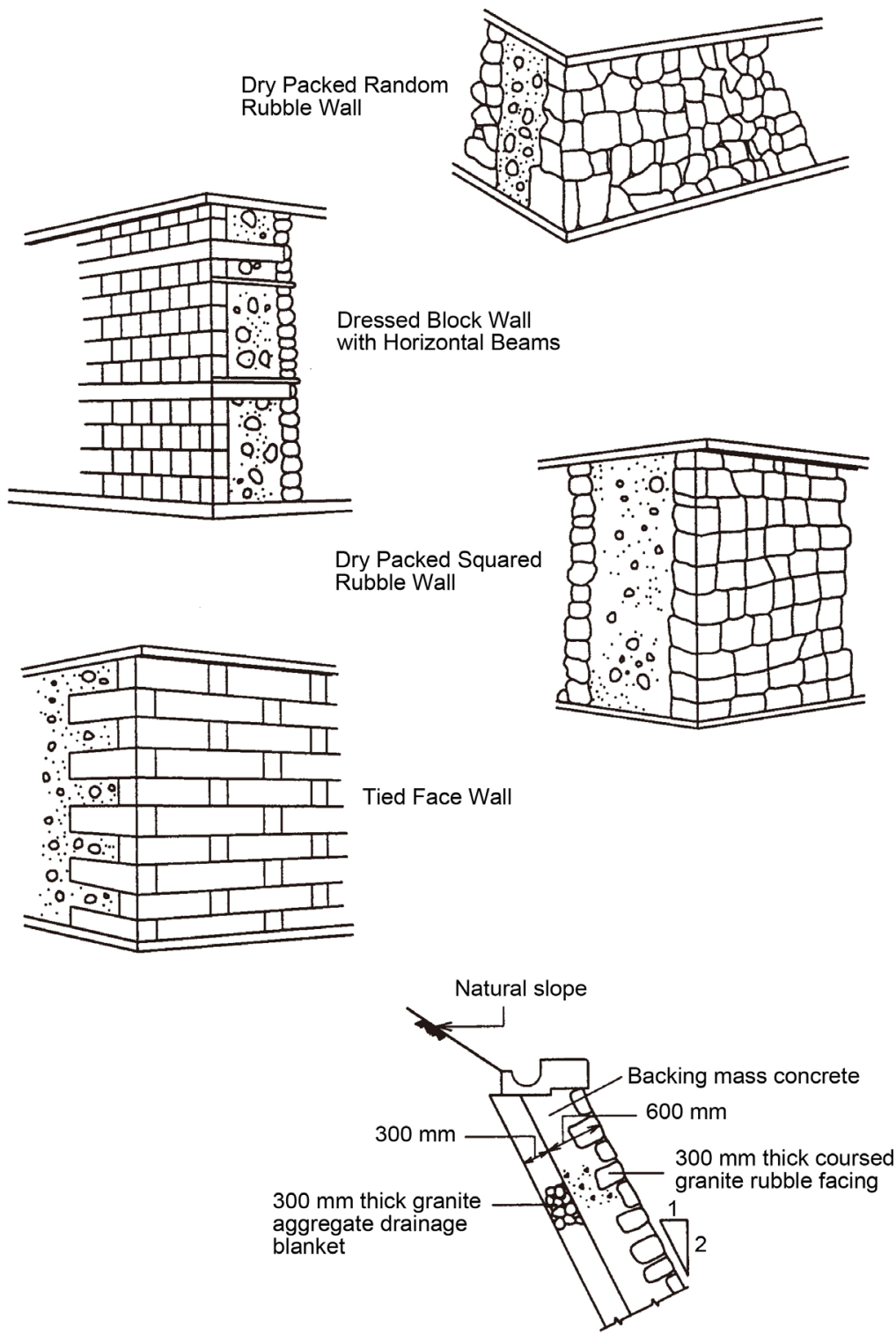

Typical stone pitching details

Figure 1. Types of retaining walls used in Hong Kong [5]. 
into two groups: Pre-war and post-war [4].

Post-war structures, which are mainly cantilever, counterfort and gravity structures, are generally designed and built in accordance with engineering principles [5]. However, pre-war walls are largely gravity structures of masonry or mass concrete construction. The condition and the geometry of these walls require new investigations to test their stability and integrity [5].

When, in 1995, the Geotechnical Engineering Office (GEO) invited six contracting firms to take part in a site characterisation study to determine the possible uses of geophysical techniques for the assessment of subsurface stability indicator [4], GPR was one of the non-invasive methodologies considered to determine possible slope instabilities. Geophysical techniques are more effective when studying old masonry walls than slopes because walls have a more clearly defined structure [5].

This paper focuses on the GPR survey carried out by two of those subcontractors on a specific site using different frequencies $(200 \mathrm{MHz}$ and $35 \mathrm{MHz}$ for Fugro and $500 \mathrm{MHz}$ and $100 \mathrm{MHz}$ for Golder). The results of the surveys will be compared to determine how the choice of the right frequencies might affect the interpretation of the data.

\section{Location}

The location chosen for this paper is the masonry wall near the Police Quarters on Hollywood Road. This area was built in 1951 and originally served as the first dormitory for Chinese rank and file police officers (Site F, Figure 2).

Site $\mathrm{F}$ consisted of a mortared random rubble masonry retaining wall on the southeast to northwest end. A staircase at the southeast end connected a concrete covered platform at the top of the wall to a play area at the bottom [6]. This area was investigated using four horizontal drill holes (Figure 3(a)) and two trial pits located on the western part of the terrace above the retaining wall (Figure 3(b)). GPR and Resistivity Imaging survey were carried out in October 1996.

\section{Methodology}

The centre frequencies of commercial GPR antennas typically range from 25 $\mathrm{MHz}$ to $4 \mathrm{GHz}$ [3]. Generally there is a direct relationship between the transmitter frequency and the resolution that can be obtained. At the same time, there is an inverse relationship between frequencies and penetration depth. For civil engineering purposes, most of the GPR frequencies range between $1.5 \mathrm{GHz}$ and $400 \mathrm{MHz}$, for which the penetration is between 0.3 and $2 \mathrm{~m}$.

While metallic targets are very good reflectors and PVC pipes generally produce much weaker signals, the presence of moisture and clay can also limit the signal penetration. Other external factors that might affect the performance are site topography and vegetation, as well as weather conditions [3].

The presence of kaolinite clays, which are most commonly derived from weathered granites, gives reasonable results during the survey, whereas montmorillonite clays derived from weathered basalts have much higher signal at- 


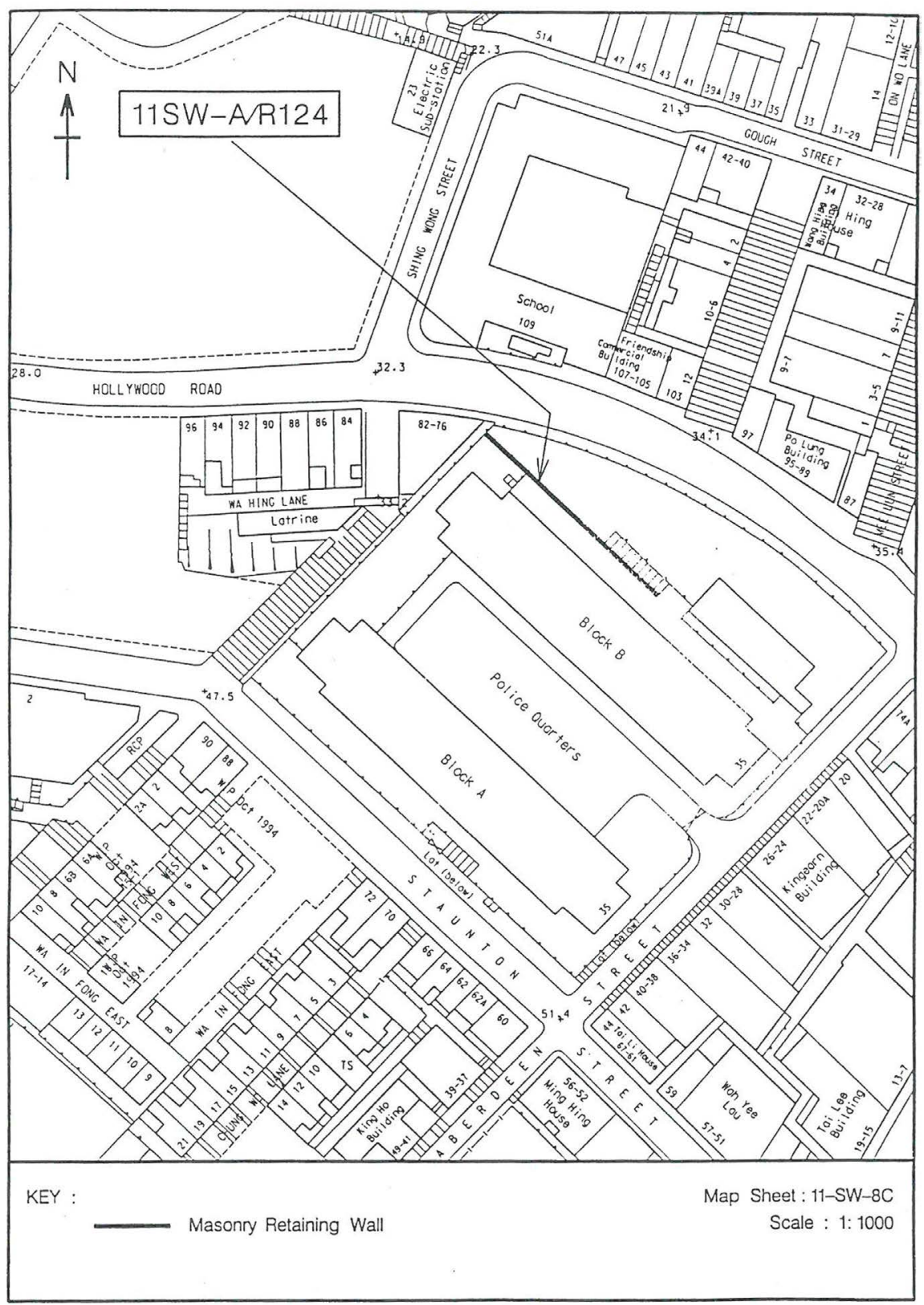

Figure 2. Site F (@Slope Information System 2016).

tenuation rates [3].

The ground resolution also depends upon a series of other factors such as:

- Amplitude and wave length of the transmitted pulse;

- The electrical properties and electromagnetic propagation characteristics of the host material;

- The complexity of the geology;

- Noise;

- Depth shape and size of the target;

- Electrical impendance of the target [7].

Attenuation of the GPR signal can be caused by conductivity losses and dielectric or magnetic absorption. Conductivity losses are the most common 


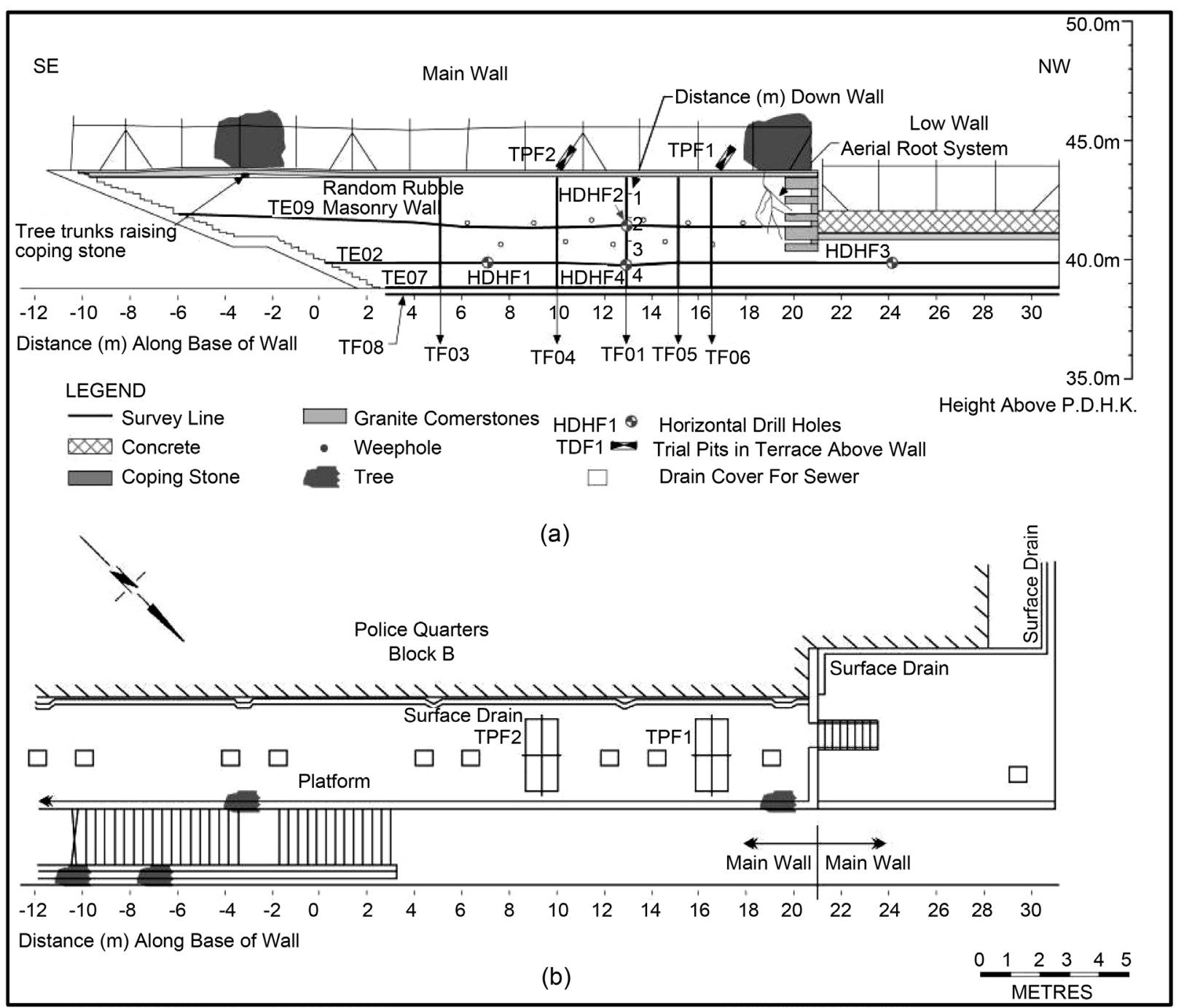

Figure 3. (a) Front elevation of the wall at Hollywood Road Police Quarters. (b) Plan of the wall and platform at Hollywood Road Police Quarters [5].

within geological materials [8].

The Geotechnical Engineering Office (GEO) determined that on Site F, the location of two traverse lines (TF-01 and 02) was to be surveyed using GPR. Other than that, the contractor could decide on the frequency to be used, as well as whether or not to survey the other traverses.

For their survey, Fugro used both $35 \mathrm{MHz}$ and $200 \mathrm{MHz}$ frequencies for all the traverses (TF01 to 08). Golder, on the other hand, used two different frequencies for the GPR survey at Site F: a $500 \mathrm{MHz}$ antenna on TF1 to TF6 and a lower frequency (100 MHz) one on TF02 [5].

\section{Results}

The GPR surveys carried out by the contractors produced very different results. Fugro's high frequency $(200 \mathrm{MHz})$ accurately identified features near the surface (Figure 4). Granite and volcanic boulders were easily recognised, as well as subvertical features interpreted as drainage pipes. 


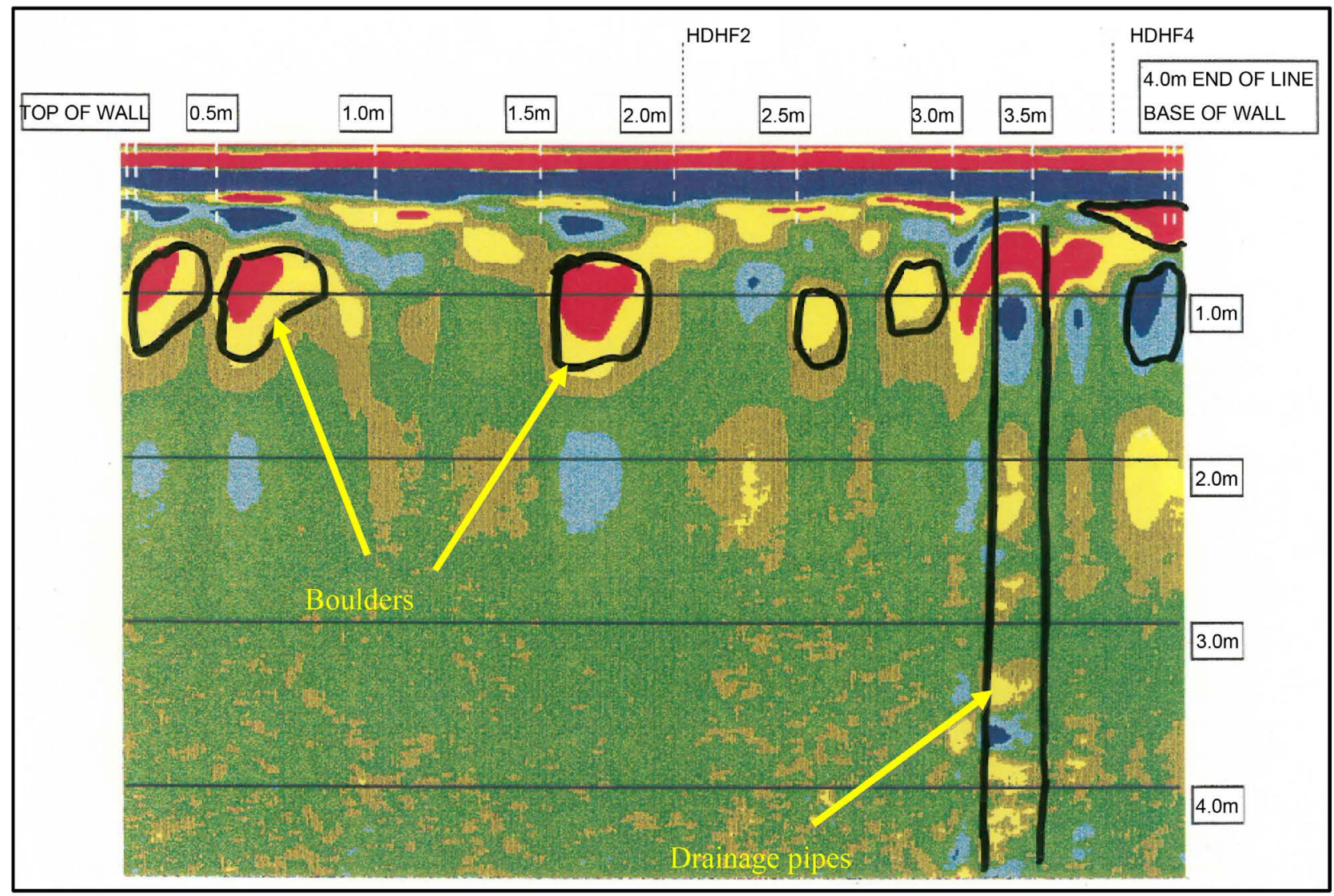

Figure 4. Results with $200 \mathrm{MHz}$ antenna (@Fugro Report 1997).

Horizontal boreholes were drilled on the Site F wall and the cores showed the heterogeneity of the fill material, which contained large boulders also visible through the GPR survey. The trench pits excavated also confirmed the nature of the fill deposit, containing bricks, fragments of concrete slabs and metal objects easily picked up by the $200 \mathrm{MHz}$ antenna. However, it is important to note that the thickness of the retaining wall was not so clearly marked.

The survey carried out by the same contractor at $35 \mathrm{MHz}$ aimed, instead, to identify deeper features that would be out of the reach of higher frequencies. The results show the disappearance of the shallow features and the presence of a few parallel to sub-parallel linear features located between 2.5 to $10 \mathrm{~m}$ away from the surface (Figure 5). Initially they were interpreted as the interface between the fill deposit and the completely decomposed granite (CDG). However, none of the boreholes or the trench pits confirmed this interpretation.

The results obtained by the GPR survey highlight that the antenna at $200 \mathrm{MHz}$ works very well to define superficial features present in the slope. It does not, however, define the true thickness of the masonry wall. In cases such as the collapse of the retaining wall in Kwun Lung Lau, the earlier identification of the type and size of masonry may have prevented such an event.

Golder obtained better results at the same location using two frequencies: 100 and $500 \mathrm{MHz}$ [5]. The $500 \mathrm{MHz}$ frequency allowed the radargram to identify the 


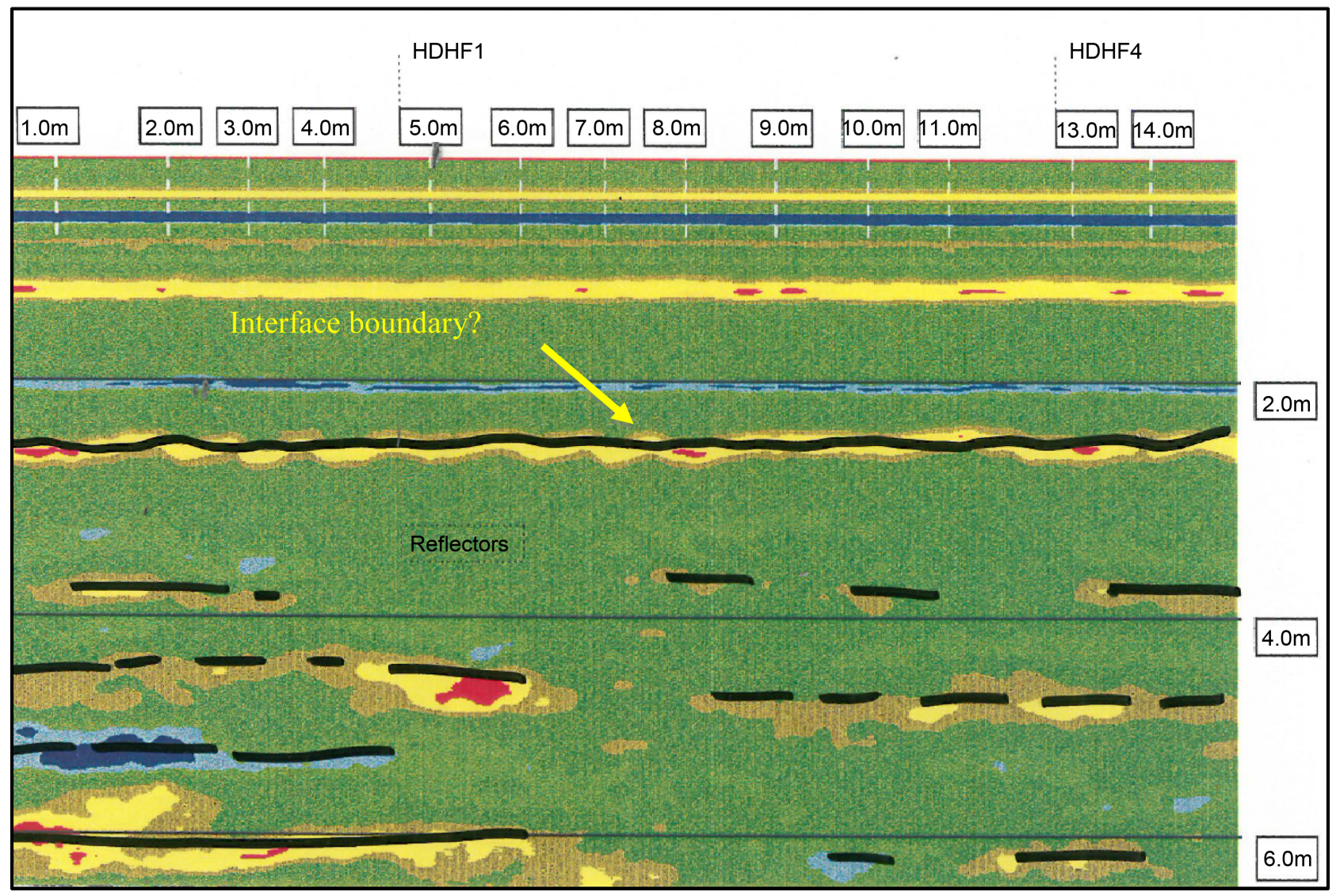

Figure 5. Results with $35 \mathrm{MHz}$ antenna (@Fugro Report 1997).

thickness of the masonry wall. Other important features were also picked up with this frequency, features such as a granite-lined sewer system and loose cobble and boulder fill with concrete, brick fragments and voids in the trench dug for the new sewer [5].

The $100 \mathrm{MHz}$ frequency identified few coherent reflectors at a depth of 2 - 3 meters into the wall. The radar energy appears to be severely attenuated by the material present in this area. The correlation with electrical imaging indicates the presence of conductive material such as clay. The result from the $35 \mathrm{Mhz}$ survey shares some similarities in identifying such linear features.

\section{Conclusions}

This geophysical technique has potential in the assessment of the stability of the pre-war retaining walls but it is important to choose the correct frequency. The choice must be related to the aim of the survey itself. A $500 \mathrm{MHz}$ antenna provides better results than a $200 \mathrm{MHz}$ one if we want to identify the thickness of a retaining wall and the presence of any shallow features present within the fill. For deeper surveys, the $35 \mathrm{MHz}$ and $100 \mathrm{MHz}$ antennas seem inadequate to identify major features. However, these frequencies have spotted a few common reflectors that can be interpreted as air void or accumulation of clay rather than a clear interface between fill and CDG. 


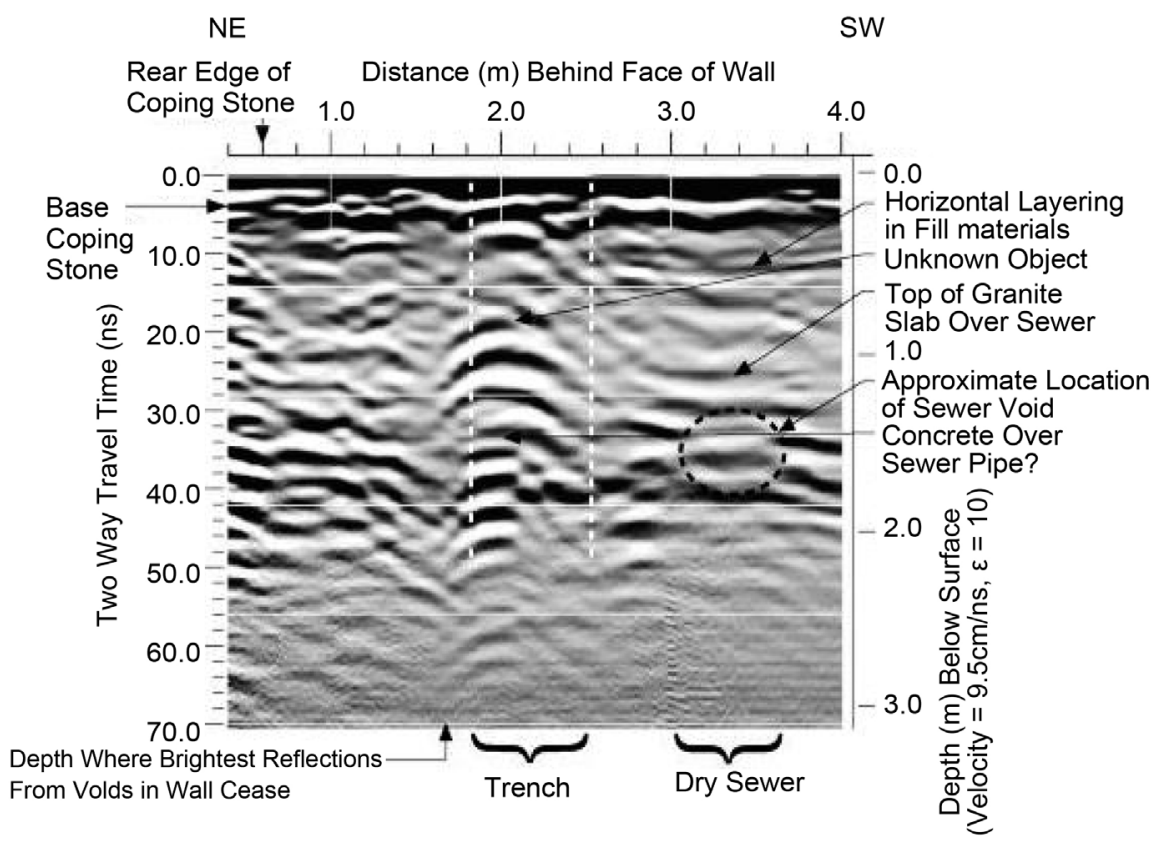

(a) Pre-migration

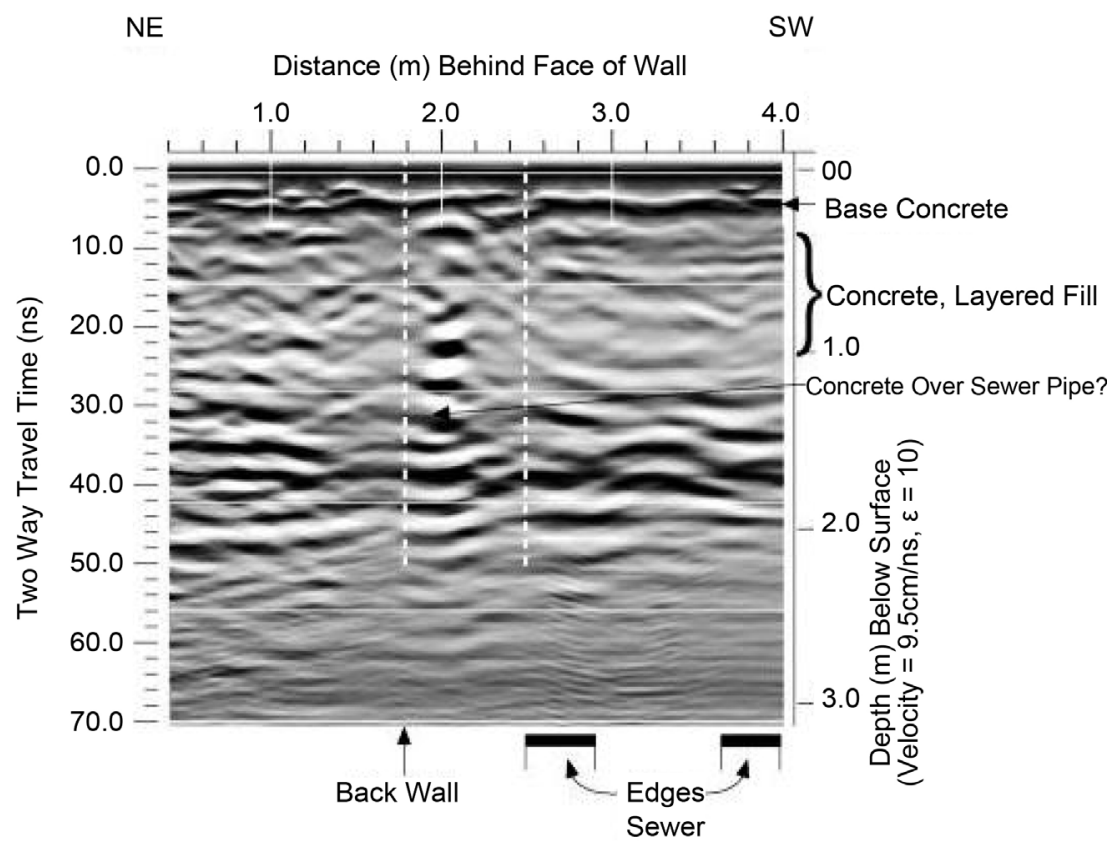

(b) After migration

Figure 6. Comparison between pre-migration and after migration signal on Golder's survey [5].

Other factors have probably played an important role in identifying the main features behind the retaining wall and improving the quality of the results. Golder, for example, repeated the traverses more than once and made adjustments to the gain levels, ranges, sampling intervals and filter readings [4]. We should also consider the importance of migration, which aside from allowing us to correctly interpret the GPR data from structurally complex areas and deter- 
mine the geometry and correct location of reflectors (or scatters) in the subsurface (Figure 6), it also provides quantitative information on the reflectivity coefficients at those surfaces or interfaces [8]. In the survey carried out by Golder, the migration process was used to successfully collapse the diffraction from an unknown piece of material such as a steel bar buried in the trench behind the wall [5].

The frequency in surveying engineering slopes has a significant impact on Ground Penetrating Radar results. Nonetheless, other elements should be taken into account so as to have better quality results, with less room for misinterpretation.

\section{Acknowledgements}

The author wishes to thank Hong Kong University Professor L. S. Chan for his help in retrieving the unpublished reports and Miss Judy $\mathrm{Wu}$ for the editing work.

\section{References}

[1] Milsom, J. and Eriksen, A. (2015) Field Geophysics, Wiley Blackwell, Chapter 10, 185-205.

[2] Fisher, S.C., Stewart, R.R. and Jol, H.M. (1992) Processing Ground Penetrating Radar (GPR) Data. CREWES Research Report, 4, 11-1 to 22.

[3] Yelf, R.J. (2007) Application of Ground Penetrating Radar to Civil and Geotechnical Engineering. Electromagnetic Phenomena, 7, 102-117.

[4] Koor, N.P. (1996) A Review of Non-Invasive Engineering Geophysical Techniques for Site Characterization. Hong Kong Interim Report, No. 2 ( $2^{\text {nd }}$ Draft).

[5] Bishop, I. and Koor, N.P. (2000) Integrated Geophysical and Geotechnical Investigations of Old Masonry Retaining Wall in Hong Kong. Quarterly Journal of Engineering Geology and Hydrogeology, 33, 335-349.

[6] Fugro Report (1997) Site "F” Masonry Wall near Police Quarters, Block B, Hollywood Road, Volume 2.

[7] Lau, K.C. (1998) A Review of Downhole Geophysical Methods for Ground Investigation. Geo Report No. 99, Geotechnical Engineering Office, Civil Engineering Department, The Government of the Hong Kong Special Administrative Region.

[8] Sena, A.R., Stoffa, P.L. and Sen, M.K. (2005) Migration of Ground Penetrating Radar Data in Heterogeneous and Dispersive Media. New Strategies for European Remote Sensing, Rotterdam, 711-719. 
Submit or recommend next manuscript to SCIRP and we will provide best service for you:

Accepting pre-submission inquiries through Email, Facebook, LinkedIn, Twitter, etc. A wide selection of journals (inclusive of 9 subjects, more than 200 journals)

Providing 24-hour high-quality service

User-friendly online submission system

Fair and swift peer-review system

Efficient typesetting and proofreading procedure

Display of the result of downloads and visits, as well as the number of cited articles Maximum dissemination of your research work

Submit your manuscript at: http://papersubmission.scirp.org/

Or contact ijg@scirp.org 